\title{
An Expanded Inventory of Conserved Meiotic Genes Provides Evidence for Sex in Trichomonas vaginalis
}

\author{
Shehre-Banoo Malik ${ }^{\text {da }}$, Arthur W. Pightling, Lauren M. Stefaniak ${ }^{\text {ab }}$, Andrew M. Schurko, John M. \\ Logsdon, Jr.*
}

Department of Biology, Roy J. Carver Center for Comparative Genomics, University of lowa, lowa City, lowa, United States of America

\begin{abstract}
Meiosis is a defining feature of eukaryotes but its phylogenetic distribution has not been broadly determined, especially among eukaryotic microorganisms (i.e. protists)—which represent the majority of eukaryotic 'supergroups'. We surveyed genomes of animals, fungi, plants and protists for meiotic genes, focusing on the evolutionarily divergent parasitic protist Trichomonas vaginalis. We identified homologs of 29 components of the meiotic recombination machinery, as well as the synaptonemal and meiotic sister chromatid cohesion complexes. T. vaginalis has orthologs of 27 of 29 meiotic genes, including eight of nine genes that encode meiosis-specific proteins in model organisms. Although meiosis has not been observed in T. vaginalis, our findings suggest it is either currently sexual or a recent asexual, consistent with observed, albeit unusual, sexual cycles in their distant parabasalid relatives, the hypermastigotes. $T$. vaginalis may use meiotic gene homologs to mediate homologous recombination and genetic exchange. Overall, this expanded inventory of meiotic genes forms a useful "meiosis detection toolkit". Our analyses indicate that these meiotic genes arose, or were already present, early in eukaryotic evolution; thus, the eukaryotic cenancestor contained most or all components of this set and was likely capable of performing meiotic recombination using near-universal meiotic machinery.
\end{abstract}

Citation: Malik S-B, Pightling AW, Stefaniak LM, Schurko AM, Logsdon JM Jr (2008) An Expanded Inventory of Conserved Meiotic Genes Provides Evidence for Sex in Trichomonas vaginalis. PLoS ONE 3(8): e2879. doi:10.1371/journal.pone.0002879

Editor: Matthew W. Hahn, Indiana University, United States of America

Received May 15, 2008; Accepted June 8, 2008; Published August 6, 2008

Copyright: (C) 2008 Malik et al. This is an open-access article distributed under the terms of the Creative Commons Attribution License, which permits unrestricted use, distribution, and reproduction in any medium, provided the original author and source are credited.

Funding: This work was supported by National Science Foundation grant MCB-0437442/ 0216702 to JML.

Competing Interests: The authors have declared that no competing interests exist.

* E-mail: john-logsdon@uiowa.edu

xa Current address: Department of Medical and Molecular Parasitology, School of Medicine, New York University, New York, New York, United States of America ab Current address: Department of Marine Sciences, University of Connecticut, Groton, Connecticut, United States of America

\section{Introduction}

Meiosis is a necessary part of sexual reproduction and a hallmark of eukaryotes that distinguishes them from prokaryotes, yet we are only beginning to understand its origin and evolution. Recent work has revealed that many meiotic genes are conserved not only among animals, fungi and plants (AFP) and some eukaryotic microorganisms (protists), but also in the putatively early-diverged protist Giardia intestinalis [1] which is not known to be sexual per se but was recently shown to have genetic recombination [2,3] and to use orthologs of meiosis-specific genes in putatively parasexual recombination processes [4]. The breadth of eukaryotic diversity lies among the protists $[5,6]$, yet much remains to be elucidated about their meiotic machinery $[1,7,8]$. Thus, we have continued and expanded our search for conserved meiotic genes in public databases and particularly in the recently completed genome of Trichomonas vaginalis [9], a member of the Parabasalia.

Parabasalids are a highly diverged eukaryotic lineage in which the molecular mechanisms of meiosis are unexamined; they are related (albeit distantly) to diplomonads (e.g. Giardia) [10-17]. Morphological and molecular phylogenetic data, while controversial in details, divide parabasalids into two groups, the hypermastigotes (symbionts of roaches and termites, e.g. Trichonymphida) and the trichomonads (parasitic and free-living flagellates, e.g. Trichomonadidae) [18-23]. T. vaginalis is sexually transmitted between people's urogenital tracts, and acute infections are associated with increased risk of pelvic inflammatory disease, HIV-1 infection, infertility and problems with pregnancy [24,25]. $T$. vaginalis is estimated to cause 174 million new infections annually worldwide and is the most common non-viral sexually transmitted human pathogen $[25,26]$. Metronidazole is commonly used to treat $T$. vaginalis infections, but resistance to the drug is increasing [27]. It is not known whether genetic exchange occurs in populations of $T$. vaginalis; however, genetic exchange could mediate the proliferation of drug-resistant mutations or increased virulence in populations of the parasite.

While neither meiosis nor sex has been observed in Trichomonas or other trichomonads, various observations suggest the presence of sexual processes in Parabasalids. Using light microscopy, Cleveland described insect-hormone-induced divisions in hypermastigotes as one-step meiosis, and suggested that this was a more primitive form of meiosis than typical two-step meiosis in AFP [28-30]. For trichomonads, the finding of six genetically identical strains of $\mathcal{T}$. vaginalis with clonal population structure was taken as evidence against meiotic recombination [31]. However, recent phylogenetic analyses of 731 polymorphic molecular markers show genetic variation among 20 strains of $\mathcal{T}$. vaginalis that may be sufficient to indicate meiotic recombination [32]. Similar analyses reveal that closely-related T. vaginalis strains shared the phenotype of resistance to metronidazole, but this pattern had no correlation with geographical origin [33], suggesting the genetic spread of resistance by recombination and strong selection. The recent identification of 
mariner, Maverick and other DNA transposons in high copy number [34-36] in the highly repetitive $>160 \mathrm{Mb}$ genome sequence of $T$. vaginalis strain G3 [9,37] could be the result of a predominantly asexual mode of reproduction or the recent loss of sexual reproduction [38]. In contrast, the presence of intact retroposons and reverse transcriptase homologs in the $T$. vaginalis strain G3 genome sequence [9] is consistent with an expectation that such elements, that are predominantly vertically transmitted, are only maintained in sexual lineages [39]. Although meiosis was not observed in extensive cytological studies of cell division in $T$. vaginalis $[40,41]$, it has been noted that its six chromosomes may be synapsed in $0.1 \%$ of cells, suggesting that meiosis may occur transiently in lab populations [42]. Quadrinucleated cells transiently observed in lab populations were noted but dismissed as not indicating a developmental stage in $T$. vaginalis [43]. Thus, with little direct evidence for meiosis in $\mathcal{T}$. vaginalis, an inventory of meiotic genes will be an informative tool with which to assess its ability to undergo sexual processes.

Meiosis remains to be described at the molecular level in parabasalids and in most other protist lineages. Since parabasalids could represent one of the earliest diverging lineages on the tree of eukaryotes [11-14] and they may employ non-canonical meiosis, their meiotic processes could represent an ancestral state. Thus, an understanding of the molecular mechanisms underlying meiosis in these protists is important. Comparative studies of meiotic machinery (i) may indicate the presence of sexual reproduction in recent ancestors of organisms that are sexual or truly asexual (vs. just facultatively sexual), (ii) could indicate the absence of sex, (iii) will be useful for studies of the evolutionary advantages of sex, and (iv) can provide data that are valuable for ecological and epidemiological studies [44]. Surveys of meiotic genes have not been performed in most protists, making a comparative analysis of meiosis incomplete due to the limited available gene sequence data from diverse protists [45]. Thus, the universality of meiotic machinery in eukaryotes remains an open question.

We surveyed the genomes of Trichomonas vaginalis (strains G3 and $\mathrm{NIH}-\mathrm{Cl}$ ) and other diverse eukaryotes for a previously-described set of 17 conserved meiotic genes [1] and 12 additional meiotic genes also conserved among eukaryotes (Table 1 and Figure 1). Our search included 9 genes that are "meiosis-specific" since they are only known to function in meiosis in AFP and thus hypothesized to only be present in organisms with sexual ancestry (Spo11, Hop1, Hop2, Mnd1, Dmc1, Msh4, Msh5, Mer3, Reco). We also surveyed 20 additional genes whose products are required for meiosis in AFP but also have general functions in DNA repair or mitosis (Mre11, Rad50, Rad1, Rad52, Rad51, Msh2, Msh6, Mlh1-Mlh3, Pms1, Smc1-Smc6, Rad21, Scc3, Pds5). We searched public databases to find homologs of meiotic proteins in diverse eukaryotes with complete (at least $7 \times$ coverage) genome sequence. Completed and near-complete genome sequences include AFP and representative apicomplexan, ciliate, chromist, amoebozoan, trypanosomatid and diplomonad protists, in addition to $T$. vaginalis. Meiotic gene sequences from $T$. vaginalis strain G3 found by this method were amplified by the polymerase chain reaction (PCR) from strain NIH-C1 and sequenced. Homology of the meiotic proteins was validated by phylogenetic analysis, by which we determined if the homologous genes were orthologs (related by speciation events) or paralogs (related by gene duplication). Our results indicate that homologs of a diverse set of meiotic genes are widespread among eukaryotes.

\section{Results and Discussion}

We present our inventory of meiotic genes found in T. vaginalis in the context of an expanded set of 29 meiotic genes conserved among over 30 AFP and protist genomes (Table 2). Of the 29 meiotic genes surveyed, 27 have homologs in the $T$. vaginalis genome; homologs of the meiosis-specific sister chromatid cohesin Rec8 and the DNA repair protein Rad52 were not found. The 29 genes surveyed from the five of six major eukaryotic lineages [11] for which complete genome sequence data are available (Opisthokonta, 'Amoebozoa', 'Archaeplastida', 'Chromalveolata' and 'Excavata') include 17 genes previously reported as "core meiotic machinery" [1]. The large number of meiotic genes shared by $T$. vaginalis, mammals (e.g., Homo) and fungi (e.g., Saccharomyces) suggest that putative meiotic processes in $T$. vaginalis could resemble those in mammals and fungi. In contrast, Giardia intestinalis, the other putatively asexual early-branching protist in our study, lacks eight of 29 meiotic genes, and Drosophila melanogaster, a sexual organism, is missing ten. G. intestinalis was recently shown to utilize three of its meiosis-specific protein homologs (Spol1, Hopl and Dmcl) to mediate homologous recombination (but not meiosis) in the nuclei of cysts in a process named diplomyxis [4]. Together, our data and these observations suggest that $T$. vaginalis may be equipped to perform meiotic recombination or similar parasexual process by using its meiotic gene homologs.

We found non-identical copies of eleven meiotic genes in $\mathcal{T}$. vaginalis that are usually found as single copies in other eukaryotes (Tables 2, 3 and Table S1.1 in Supporting Information File S1). We cannot discern whether all of the copies are functional given the limited gene expression information available. However, our phylogenetic analyses show that these genes have evolved by recent duplications (within parabasalids) and, in most cases, one copy is more conserved than the others. Consistent with that observation, duplications within families of Trichomonas vaginalis protein-coding genes likely occurred after its divergence from sister taxon Trichomonas tenax [9]. The frequency of recently duplicated meiotic genes observed in $T$. vaginalis approaches that seen in some plants and fish (Table 2), which are both thought to have polyploid origins. Six of the eleven genes present in multiple copies in $T$. vaginalis (Table 3 ) are uniquely duplicated in $T$. vaginalis and not in any other organism included in our study. Duplications of chromosomes, segments of chromosomes, and possibly whole genomes as in some plants and fish might explain the presence of extra copies of meiotic genes in T. vaginalis. If so, these genes are putative homeologs or ohnologs - duplicated genes arising from polyploidization events [46]. Since the $T$. vaginalis genome sequence is highly repetitive and consists of 17,290 unordered scaffolds [9], additional data and analyses to better assemble the genome sequence into a smaller number of longer and ordered scaffolds are required to understand how chromosome- and genome-scale duplication contributed to its genome architecture. Ten of eleven recently duplicated meiotic genes were located on separate scaffolds. However, the two Rad50 gene copies were found in an inverted tandem repeat on the same scaffold of assembled genome sequence, an arrangement which is inconsistent with polyploidization and that might result from ectopic meiotic sister chromatid recombination [47]. Our sequences from T. vaginalis strain NIH-C1 revealed that Rad51b, Scc3b and Pds5 differed in the number of short tandemly repeated sequences within their coding regions when compared with the genome sequence of $T$. vaginalis strain G3. These duplicate genes (Rad51b and $S c c 3 b)$ may also be derived from allelic divergence resulting from the accumulation of mutations during extensive asexual (mitotic) reproduction [48]. If this is the case, T. vaginalis may be facultatively sexual or asexual.

To assess if the $T$. vaginalis meiotic genes are functional, we queried two expressed sequence tag (EST) databases and found 
Table 1. Core meiotic genes and some key functions of their encoded proteins in meiosis.

\begin{tabular}{|c|c|}
\hline Protein & Function \\
\hline Spo11 & Transesterase, creates DNA double-strand breaks (DSB) in homologous chromosomes [103-105]. \\
\hline Mre11 & $3^{\prime}-5^{\prime}$ dsDNA exonuclease and ssDNA endonuclease, trims back broken DNA ends and hairpins [106-108]. \\
\hline Rad50 & Dimer, holds broken DNA ends together while Mre11 trims. ATPase, has DNA-binding activity $[105,108]$. \\
\hline Rad1 (Mei9) & $\begin{array}{l}\text { Forms a heterodimer with Rad10 (Ercc1) [109]. } 5^{\prime}>3^{\prime} \text { endonuclease, essential for nucleotide excision repair. Required for meiotic crossing } \\
\text { over, normal meiotic chromosome disjunction, to repair mismatches in heteroduplex DNA and to resolve reciprocally exchanged } \\
\text { recombination intermediates in Drosophila [110]. }\end{array}$ \\
\hline Hop 1 & $\begin{array}{l}\text { Protein that binds DSBs and oligomerizes early during meiotic prophase, and forms axial and lateral elements of the synaptonemal complex } \\
\text { [111]. }\end{array}$ \\
\hline Hop2 & $\begin{array}{l}\text { With Mnd1, ensures accurate and efficient homology searching, downstream of Rad51 and Dmc1, during pachytene stage of meiotic } \\
\text { prophase [112]. }\end{array}$ \\
\hline Mnd1 & With Hop2, functions after meiotic DSB formation, and required for stable heteroduplex DNA formation [113]. \\
\hline Rad52 & $\begin{array}{l}\text { Binds to the ssDNA ends of DSBs and initiates DSB repair by homologous recombination [114]. Stimulates Rad51-mediated strand invasion by } \\
\text { interaction with Rad51 and RPA, and promotes single strand annealing (SSA) [115]. }\end{array}$ \\
\hline Dmc1 & Meiosis-specific homolog of Rad51, has similar function but promotes interhomolog recombination [116-118]. \\
\hline Rad51 & $\begin{array}{l}\text { Forms helical filaments on single-stranded and double-stranded DNA and catalyzes homologous DNA pairing and strand exchange. } \\
\text { (Intrahomologous recombination) }[116,118] \text {. }\end{array}$ \\
\hline Msh4 & $\begin{array}{l}\text { Forms a heterodimer with Msh5, interacts with Mlh1/Mlh3 heterodimer. Directs Holliday junction resolution towards crossover with } \\
\text { interference [119]. }\end{array}$ \\
\hline Msh5 & $\begin{array}{l}\text { Forms a heterodimer with Msh4, interacts with Mlh1/Mlh3 heterodimer. Directs Holliday junction resolution towards crossover with } \\
\text { interference [119]. }\end{array}$ \\
\hline Msh2 & Forms a heterodimer with Msh3 or Msh6 [119]. \\
\hline Msh6 & Forms a heterodimer with Msh2, binds base-base mismatches [119]. \\
\hline Mlh1 & Mismatch repair of dinucleotide and trinucleotide sequences, interacts with Msh2, forms heterodimers with Mlh2, Mlh3 and Pms1 [119]. \\
\hline Mlh2 & Forms a heterodimer with Mlh1. Interacts with Msh2/3 or Msh2/6 for removal of cisplatin adducts [119]. \\
\hline Mlh3 & $\begin{array}{l}\text { Forms a heterodimer with Mlh1. Interacts with Msh2/3 or Msh2/6 for frameshift repair in mitosis or meiosis, or with Msh4/5 to promote } \\
\text { meiotic crossovers [119]. }\end{array}$ \\
\hline Pms1 & Mismatch repair. Interacts with Msh2/3 or Msh2/6 as a heterodimer with Mlh1[119]. \\
\hline Mer3 & $\begin{array}{l}\text { Meiosis-specific DEAD-box helicase that promotes Holliday junction resolution with crossover interference together with ZMM proteins, } \\
\text { including Msh4 and Msh5 }[57,58,120-122] \text {. }\end{array}$ \\
\hline Smc1 & Forms a heterodimer with Smc3 to form core sister chromatid cohesin subunits, with ring shape around sister chromatids $[123,124]$. \\
\hline Smc2 & Forms a heterodimer with Smc4 to form core condensin subunits, ring shape, essential for chromosome assembly and segregation. [123] \\
\hline Smc3 & Forms a heterodimer with Smc1 to form core sister chromatid cohesin subunits, with ring shape around sister chromatids $[123,124]$. \\
\hline Smc4 & Forms a heterodimer with Smc2 to form core condensin subunits, ring shape, essential for chromosome assembly and segregation [123]. \\
\hline Smc5 & Forms a heterodimer with Smc6 (Rad18) and is involved in DNA repair and checkpoint responses [123]. \\
\hline Smc6 (Rad18) & $\begin{array}{l}\text { Binds ssDNA, has important role in postreplication DNA repair [125]. Forms a heterodimer with Smc5 and is involved in DNA repair \& } \\
\text { checkpoint responses [123]. }\end{array}$ \\
\hline Rad21 (Scc1) & $\begin{array}{l}\text { Holds Smc1 and Smc3 heads together by binding } \mathrm{N} \text {-terminal domain to Smc3 and C-terminal domain to Smc1, thus holding sister } \\
\text { chromatids together during mitosis and meiosis [124]. }\end{array}$ \\
\hline Rec8 & $\begin{array}{l}\text { Meiotic homolog of Rad21. Holds Smc1 and Smc3 heads together by binding N-terminal domain to Smc3 and C-terminal domain to Smc1, } \\
\text { thus holding sister chromatids together during meiosis [126]. }\end{array}$ \\
\hline Scc3 & $\begin{array}{l}\text { Necessary for sister chromatid cohesion, and required for DSB repair [127]. Interacts with Smc1, Smc3 and Rec8/Rad21 in holding cohesin } \\
\text { ring together. }\end{array}$ \\
\hline Pds5 & Important for maintenance of sister chromatid cohesion in late prophase [127]. \\
\hline
\end{tabular}

Genes encoding meiosis-specific proteins are highlighted in grey.

doi:10.1371/journal.pone.0002879.t001

evidence of the transcription of some genes (Table S1.1 in Supporting Information File S1). ESTs derived from normal asynchronized cultures were found for Rad50a, Rad1, Dmc1, Msh2, Smc1b, Smc5b, Smc6, Rad21b and Pds5. In low-iron conditions, Msh5, Smc1a, Smc5a, Rad21b and Scc3a are transcribed, while ESTs encoding Rad51a were found from G2/M trophozoites. Cells exhibiting vaginal epithelial cell mediated cytoadherence expressed $S m c 2$, and ESTs encoding $S m c 1 b$ and $S m c 4 b$ were found from cold-induced pseudocysts ("compact non-motile forms without a cyst wall" [40]). These data are consistent with the expression of many (18 of 37) of the genes in our survey. However, the available ESTs may not represent conditions that promote meiosis, and their small numbers are consistent with the possibility that a given gene is expressed at low levels, or even posttranscriptionally down regulated. Of the 18 meiotic genes found in ESTs, Dmc1 and Msh5 are the only meiosis-specific gene orthologs found to be expressed in the available small sample of ESTs. The expression of Dmc1 and Msh5 orthologs suggests that meiotic recombination may occur in T. vaginalis in asynchronous cells and during low iron conditions (stress). In sum, the EST data are 


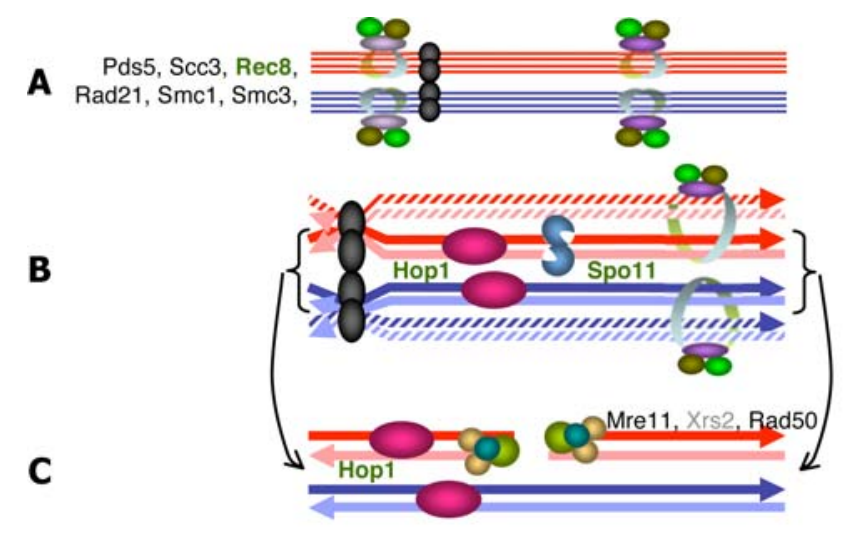

D

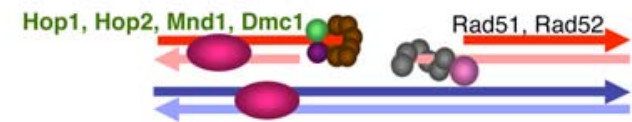

$\mathbf{E}$

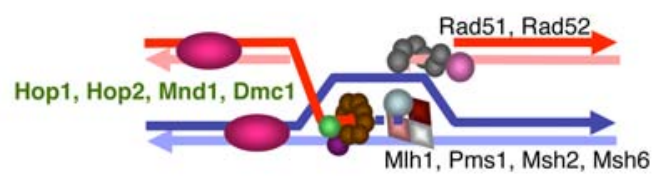

$\mathbf{F}$

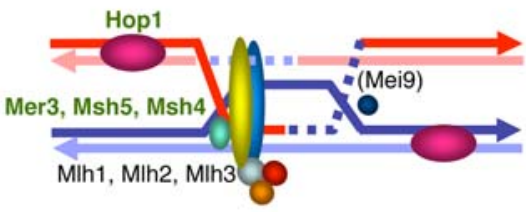

G

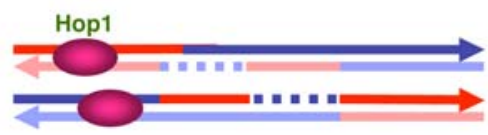

H

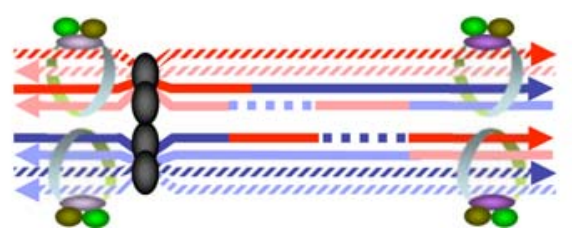

Cohesins bind to sister

chromatids (red, blue) of a

homologous chromosome pair,

attached at the centromere.

Double-strand DNA break made in a

sister chromatid. Axial elements of

synaptonemal complex are formed.

Resection of DNA ends,

Spo11 released from DNA.

Attachment of interhomolog recombination proteins.

Strand invasion, DNA synthesis

and mismatch repair.

Holliday junction resolution.

Resolved crossover.

\author{
Resolved crossover viewed in \\ context of homologous \\ chromosomes paired at the \\ centromere.
}

Figure 1. The double-strand break repair model of meiotic recombination, depicting interactions among proteins included in this study. The names of meiosis-specific proteins are highlighted in green. Exact stoichiometry is not implied. In meiosis I, cohesins bind to sister chromatids (A), after which double-strand DNA breaks are made by Spo11 (accessory proteins not shown) and the axial elements (Hop1) of the synaptonemal complex are formed (B). Double strand break repair is initiated (coupled with (B) in S. cerevisiae) and Hop 1 forms lateral elements of the synaptonemal complex (C). Strand exchange proteins are attracted to the double-strand break (accessory proteins not shown) (D). The resulting heteroduplex (E) may be resolved by crossovers, which utilize meiosis-specific proteins (F), or by gene conversion, which does not $(\mathbf{G}$, proteins not shown). This model is based primarily upon details from S. cerevisiae, but includes details from mammals for Msh4 and Msh5, and speculates on the role of Drosophila Mei-9 (Rad1) in (F) as reviewed by [54,97-100]. Table 1 gives additional details and references.

doi:10.1371/journal.pone.0002879.g001

consistent with homologous recombination (and possibly meiosis) occuring in asynchronous cells, G2/M trophozoites and pseudocysts, as well as during low iron conditions and cytoadherence to vaginal epithelial cells.

\section{Phylogenetic inference of orthology and paralogy of meiotic proteins}

Our revised inventory of meiotic proteins that spans an additional breadth of organisms with completely sequenced genomes allows us to elucidate the sexual status of basal eukaryotes. We have identified homologs of meiotic genes among organisms that may span most of the deepest divergences among eukaryotes by using phylogenetic inference to assess the evolutionary history of each of meiotic protein homolog. This approach allows evaluation of the origin and evolution of meiosis in the context of the common ancestor of eukaryotes (Figure 2 and Table 2).

Many of the meiotic genes analyzed have homologs in prokaryotes while others are limited to eukaryotes (Table 2). There are prokaryotic homologs of 21 of the 29 meiotic genes (i.e., 


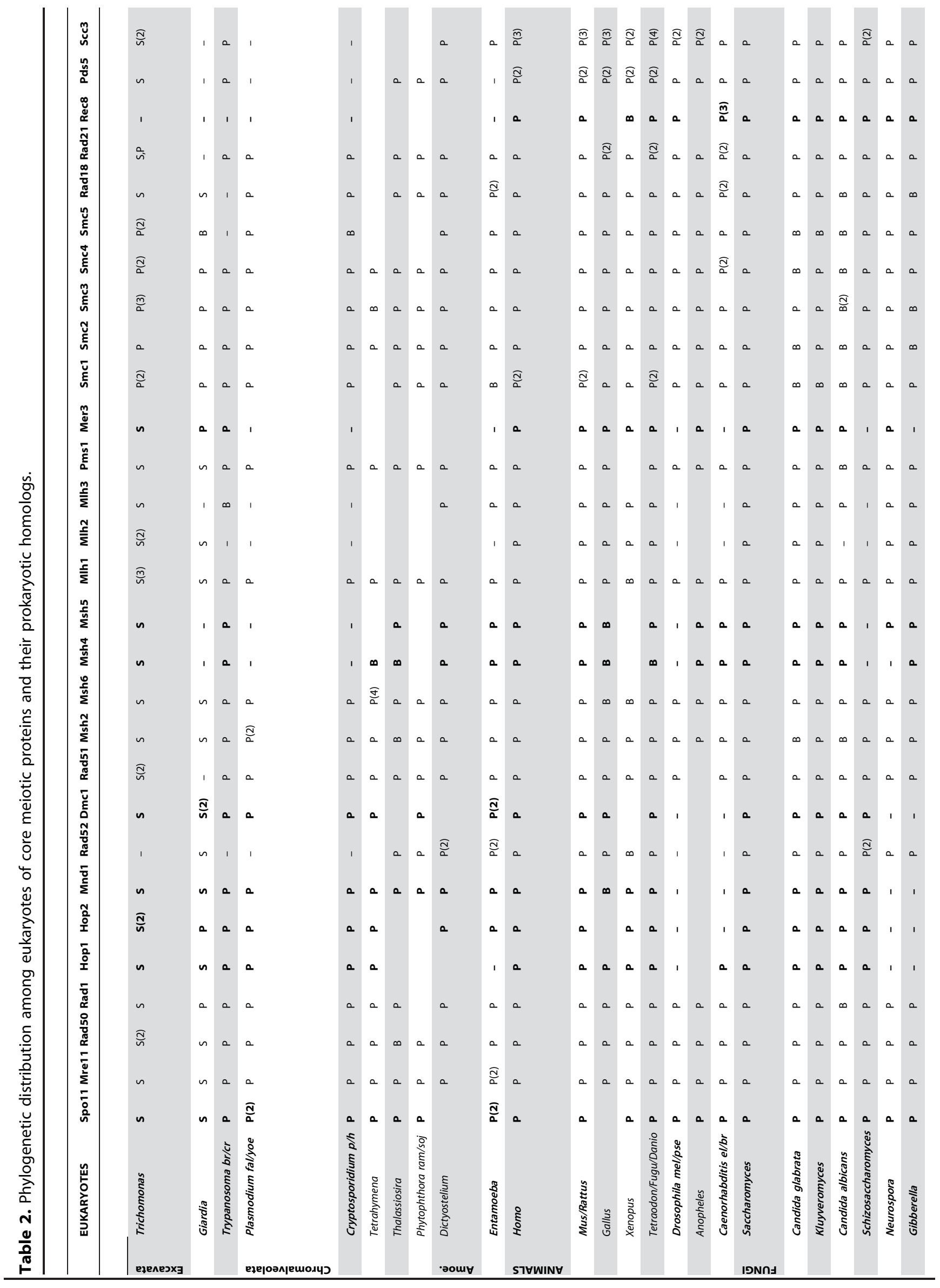




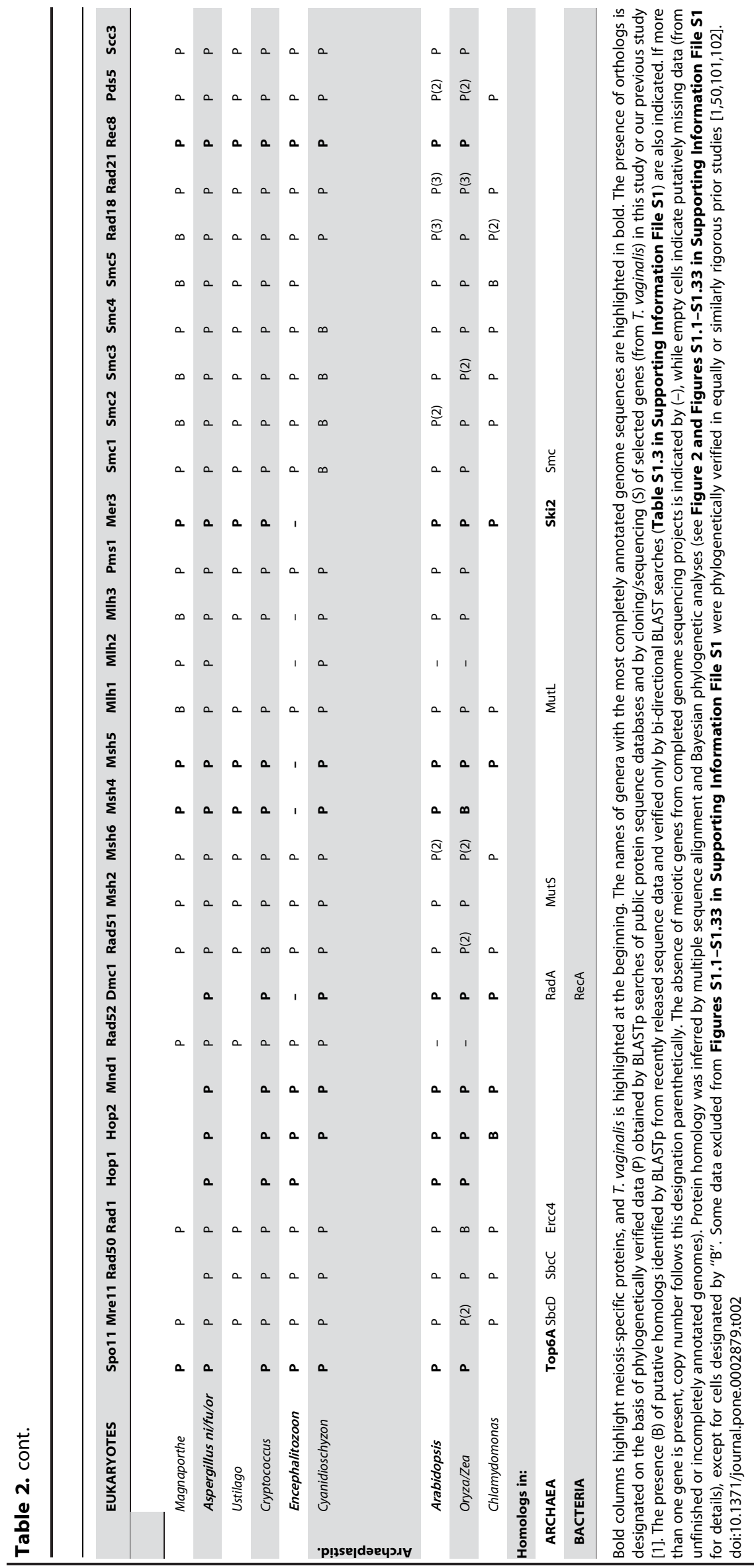


Table 3. Meiotic genes duplicated recently in T. vaginalis.

\begin{tabular}{lll}
\hline Gene name & \# of copies & $\%$ nucleotide identity \\
\hline Hop2 $(a, b)$ & 2 & $63 \%$ \\
$\operatorname{Rad50}(a, \Psi)$ & 2 & $44 \%$ \\
$\operatorname{Smc1}(a, b)$ & 2 & $45 \%$ \\
$\operatorname{Smc3}(a, b, c)$ & 3 & $53-54 \%$ \\
$\operatorname{Smc4}(a, b)$ & 2 & $56 \%$ \\
$\operatorname{Smc5}(a, b)$ & 2 & $53 \%$ \\
$\operatorname{MIh} 1(a, b, c)$ & 3 & $40-46 \%$ \\
$\operatorname{MIh} 2(a, \Psi)$ & 2 & $8 \%$ \\
$\operatorname{Rad51}(a, b)$ & 2 & $76 \%$ \\
$\operatorname{Rad} 21(a, b)$ & 2 & $17 \%$ \\
$\operatorname{Scc} 3(a, b)$ & 2 & $50 \%$ \\
\hline $\operatorname{Sin}$
\end{tabular}

Summarized from Table S1.2 in Supporting Information File S1. All duplicates trace to within parabasalids since their phylogenies show no intervening lineages, with three exceptions (Smc1, Smc3, Mlh2) that can be attributed to rapid rates of evolution.

doi:10.1371/journal.pone.0002879.t003

Spo11, Mre11, Rad50, Rad1, Dmc1, Rad51, Mer3, Msh2-6, Mlh1-3, Pms1, Smc1-6 are orthologs of prokaryotic Top6a, SbcD, SbcC, Ercc4, $\operatorname{RecA}$, Ski2, MutS, MutL, and Smc, respectively). Of these, Spo11, Dmc1, Rad51, Mer3, Msh2-6, Mlh1-3, Pms1, and Smc1-6 belong to multigene families that evolved from prokaryotic orthologs by gene duplication in eukaryotes; Mre11, Rad50 and Rad1 are nonduplicated genes with prokaryotic orthologs. Eight of the meiotic genes are apparently limited to eukaryotes (i.e., Hop1, Hop2, Mnd1, $\operatorname{Rad52,} \operatorname{Rad} 21, \operatorname{Rec} 8, P d s 5, \operatorname{Scc} 3)$ and either arose during eukaryotic evolution or diverged markedly beyond recognition from prokaryotic ancestors; all eight have experienced gene duplication events in their eukaryotic evolutionary histories. All 29 meiotic genes in our inventory are widespread among AFP and protists.

Figure 2 highlights the phylogenies of four of eight meiosisspecific proteins found in T. vaginalis: Hop2, Mnd1, Spoll and Mer3. Hop2 and Mnd1 homologs (Figures 2A and 2B) are apparently limited to eukaryotes. Spol1 (Figure 2C) has a prokaryotic ortholog (Top6A) and evolved by early eukaryotic gene duplications [49]. Mer3 (Figure 2D) also has a prokaryotic ortholog (Ski2) and belongs to a eukaryotic gene family of DEADbox helicases. In these trees, the phylogenetic resolution of some groups is limited, but our analyses clearly demonstrate orthology of each gene (Figure 2 and Figures S1.1-S1.33 in Supporting Information File S1) since $T$. vaginalis protein homologs consistently fall into groups that include proteins that were demonstrated to be meiosis-specific in AFP (as summarized in Table 1). In this study, we analyze a broader phyletic distribution of meiotic genes among eukaryotes than previously reported $[1,50]$.

In many cases, the broad survey of eukaryotes in this study enabled more precise identification of orthologous meiotic genes than previous smaller datasets permitted. The phylogeny of Hop1 orthologs rooted by distant paralogs exemplifies this improvement. Hopl is a meiosis-specific component of the synaptonemal complex. In contrast to previous results [1], the current analysis reveals the absence of a Hop1 ortholog in Drosophila, Anopheles and Neurospora and the presence of a Hop1 ortholog in Encephalitozoon and Schizosaccharomyces (Table 2). The absence of Hop1 in these three sexual animal and fungal species demonstrates that meiosis is possible without it in animals and fungi, and possibly other organisms. In contrast, the presence of Hop1 and other meiosisspecific genes (Spo11, Hop2, Mnd1 and Reco) in the putatively asexual microsporidian Encephalitozoon suggests that it may be sexual. A suite of meiosis-specific genes (Hop1, Hop2, Mnd1 and Dmc1) apparently missing in Drosophila, Anopheles and Neurospora (all sexual organisms) was previously revealed as having a patchy phylogenetic distribution $[1,55]$. However, our results show that these genes are generally conserved in most other major lineages of eukaryotes, and appear to be lost independently in different lineages, many which are known to be sexual. Caenorhabditis, nonetheless, is sexual and retains $H_{o p} 1$ homologs but lacks $H_{o p 2}$, Mnd1 and Dmc1. Interestingly, Hop2 and Mnd1 interact with Dmcl to promote interhomolog recombination in Mus and Saccharomyces [51,52]. The shared absence of Hop1 from Drosophila, Anopheles and Neurospora suggests that Hopl might also function with this suite of interacting proteins. For complexes of interacting proteins the evolutionarily conserved presence of the components suggests that their interactions are also conserved. One example of this principle is the universal presence in eukaryotes of both Mre11 and Rad50 that work together to mediate double strand break repair (Table 2).

Where previous comparative studies of meiotic genes have been taxonomically limited $[1,50,53,54]$, the distribution of meiotic gene homologs across the tree of eukaryotic life can be clarified by studying more diverse organisms. It is now clear that $S m c$ homologs are ubiquitous among eukaryotes (Table 2). The MutL homologs, Mlh2 and Mlh3 are now demonstrably widespread, being found in AFP and protists. Although previous studies revealed few protist orthologs of Msh4 and Msh5 [1,55] and suggested that the genes may have evolved recently, we find them in the genomes of several protists. Mer3 orthologs are also widely present in AFP and protists, albeit sporadically. The presence of protist orthologs of Msh4, Msh5 and Mer3, along with some apparent absences (Table 2, and Malik and Logsdon unpublished results) is readily explained by independent gene losses following the origin of paralogs by duplication. Notably, Msh4, Msh 5 and Mer3 are concomitantly missing from Plasmodium, Drosophila and Schizosaccharomyces, although all are sexual. Msh4 and Msh5 interact as a heterodimer to promote resolution of meiotic Holliday junctions with crossover interference [56], in collaboration with ZMM proteins including Mer3 [57,58]. While the presence of meiosis-specific mutS homologs Msh4 and Msh5 suggests the potential for meiosis in organisms such as Trichomonas, Trypanosoma, Entamoeba, Arabidopsis, Homo and Saccharomyces, the absence of Msh4 and Msh5 in sexual organisms indicates that meiosis can proceed without them. Thus, the presence of meiotic genes supports the hypothesis of sexuality, but the absence of a subset of genes does not exclude it.

Some meiotic genes in our survey exhibit patchy distributions (i.e. Rad52, Msh4, Msh5, Mlh2, Mlh3, Mer3, Rad21, Rec8, Pds5 and Scc3, see Table 2). While these genes are present in many AFP and some protist lineages, they are absent from others, begging the question of whether these absences are due to recent gene loss. The conserved sister chromatid cohesin proteins Pds5, Scc3, Rec8 and Rad21 all interact in a complex with Smc1 and Smc3, which in turn are both present in each complete genome surveyed for this study. The absence of Reco, Pds5 and Scc3 mainly among some protists suggests either that other proteins have evolved in these organisms to function with $\mathrm{Smcl}$ and $\mathrm{Smc} 3$ during meiosis, or that orthologs of these genes have diverged beyond current recognition, as we previously thought for Hop1 genes from Encephalitozoon and Schizosaccharomyces [1]. Conserved meiotic recombination genes (e.g., Rad52, Msh4, Msh5, Mer3, Mlh2, Mlh3) may be missing in some eukaryotes because they were dispensable in the ancestors of 

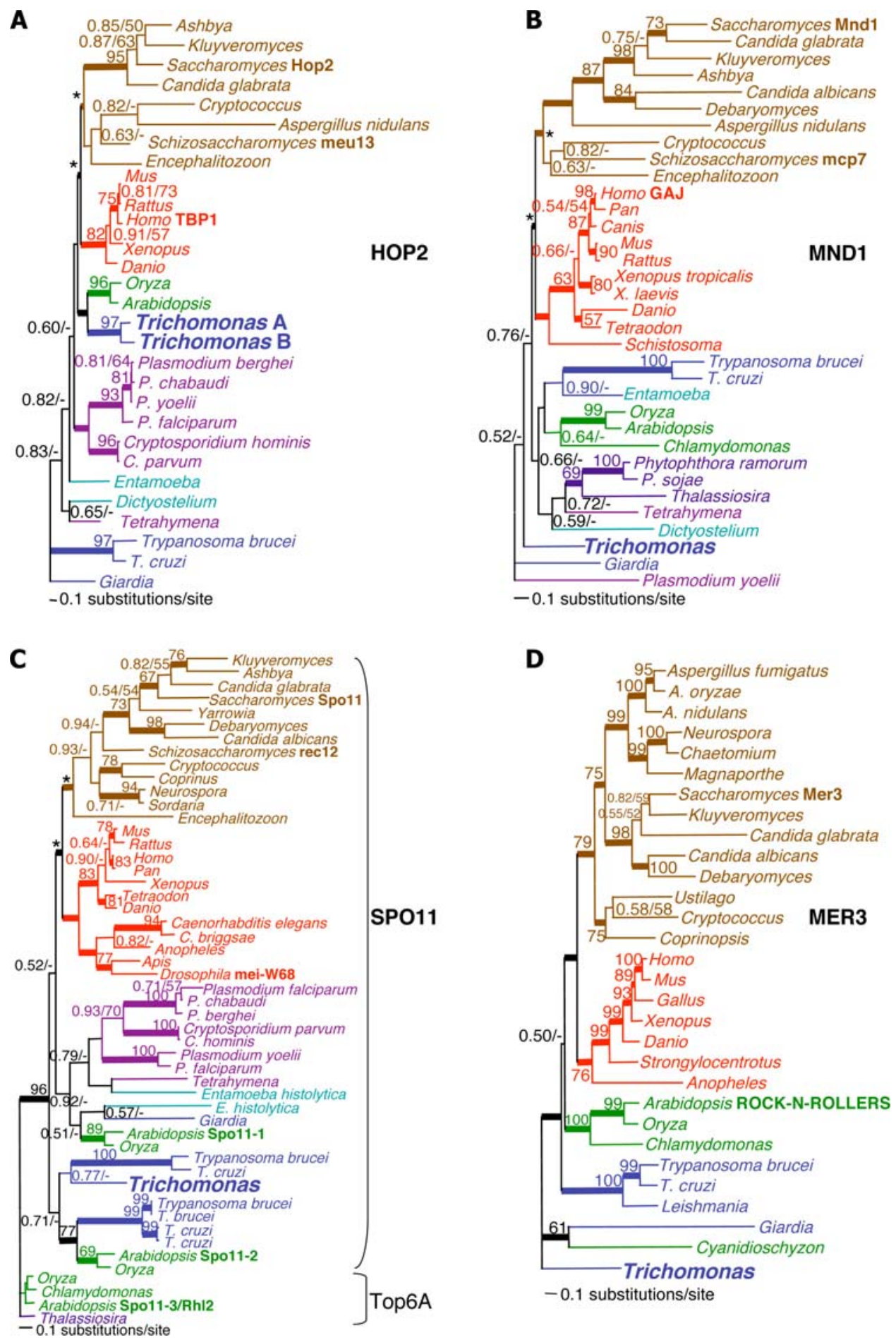

Figure 2. Phylogenetic trees for meiosis-specific proteins Hop2, Mnd1, Spo11 and Mer3. All trees shown are the consensus tree topologies determined from $\geq 700$ best trees (i.e. those with the highest posterior probabilities) inferred by Bayesian analysis using alignments of inferred proteins. Animals are indicated in red text, fungi brown, 'Amoebozoa' teal, 'Archaeplastida' in green, Alveolates plum, 'Chromista' purple, 'Excavata' blue and prokaryotes shown in black. Branches with the best support - i.e., those with 0.95 to 1.00 Bayesian posterior probabilities - have thicker lines. Numbers at the nodes indicate Bayesian posterior probability followed by percent bootstrap support from 100 replicates of PROML. An asterisk $\left(^{*}\right.$ ) denotes topological constraints placed upon the nodes uniting Fungi and Opisthokonts for Bayesian analysis. Scale bars represent 0.1 amino acid substitutions per site. Details for each tree and the accession numbers for all sequences are provided in Figures S1.1-S1.4 in Supporting Information File S1. (A) Hop2 homologs, unrooted. 167 aligned amino acid sites were analyzed, this consensus topology derived from 900 trees, $\alpha=3.86(2.71<\alpha<5.37), \mathrm{pl}=0.014(0.0004<\mathrm{pl}<0.051)$ and $\mathrm{InL}=-8363.01$. (B) Mnd1 homologs, unrooted. 202 aligned amino acid sites were analyzed, this consensus topology derived from 850 trees, $\alpha=2.80(2.18<\alpha<3.52)$, $\mathrm{pl}=0.01(0.0005<\mathrm{pl}<0.043)$ and $\operatorname{lnL}=-11589.94$. (C) Spo11 homologs, rooted with the eukaryotic Top6A paralog outgroup. 148 aligned amino acid sites were analyzed, this consensus topology derived from 700 trees, $\alpha=1.76(1.34<\alpha<2.23), \mathrm{pl}=0.10(0.03<\mathrm{pl}<0.17)$ and $\operatorname{lnL}=-10624.08$. (D) Mer3 homologs unrooted. 610 aligned amino acid sites were analyzed, this consensus topology derived from 950 trees, $\alpha=1.60(1.39<\alpha<1.83), \mathrm{pl}=0.04(0.02<\mathrm{pl}<0.06)$ and $\operatorname{lnL}=-27086.67$.

doi:10.1371/journal.pone.0002879.g002 
those organisms, and perhaps replaced by alternate DNA repair machinery. However, the general conservation of meiotic genes among diverse eukaryotes is prima facie evidence that they are ancient and were present in the common ancestor of eukaryotes, even if they may be prone to lineage-specific losses or duplications during eukaryotic evolution.

\section{Evidence for meiosis in T. vaginalis and other eukaryotes}

Although $\mathcal{T}$. vaginalis is generally considered to be asexual, our inventory of meiotic genes suggests that the capacity for meiosis was present in the last common ancestor of $T$. vaginalis and other eukaryotes. Indeed, the presence of 27 of 29 components of the meiotic machinery in $T$. vaginalis suggests that the machinery for meiotic recombination was well established before the divergence of Parabasalids and Diplomonads (e.g. Giardia). It will be necessary to determine when in the $T$. vaginalis life cycle meiosis might occur and to discern if $T$. vaginalis uses standard two-step meiosis or a putative one-step meiosis (as was described in other Parabasalids $[29,30,59])$. Such one-step meiosis (if true; see refs. [8,60]) has been suggested to be ancestral [28-30,59], but could also represent a derivative form of two-step meiosis. Since meiosis in hypermastigotes is induced in response to an insect hormone, ecdysone [29], meiosis in $T$. vaginalis might be similarly induced in response to hormones of its animal hosts. Such conditions need to be explored in detailed cytological studies of cell division in trichomonads.

A goal in searching for meiotic gene homologs in T. vaginalis was also to expand the previous inventory of meiotic genes $[1,55]$ to other diverse eukaryotes. Organisms included in this expanded phylogenomic inventory of meiotic genes include some in which sexual cycles have not been observed [61]: Cryptosporidium (an alveolate), Entamoeba (an amoebozoan), Cyanidioschyzon (a red alga), Encephalitozoon (a microsporidian, derived from Fungi) and Giardia (a diplomonad). We found orthologs of meiosis-specific genes in the genomes of each of these organisms, indicating that they all may have the potential to undergo meiosis, or that they recently diverged from a sexual ancestor. Meiosis is well known among some alveolates such as Plasmodium and Tetrahymena, included here with Cryptosporidium. Entamoeba has homologs of six of nine meiosis-specific genes, suggesting that it may be able to initiate double-strand breaks and promote interhomolog recombination and Holliday junction resolution with crossover interference. Orthologs of Mre11, Mlh3 and meiosis-specific Hop2 genes in Entamoeba and Dictyostelium, and of meiosis-specific Hop1 and Msh4 genes in Tetrahymena were recently reported to be absent $[62,63]$ according to tBLASTx and other searches; however, our results of PSI-BLASTp searches and phylogenetic analyses revealed the presence of these genes. Red algae other than Cyanidioschyzon exhibit meiosis, as evident from 1.2 billion year old fossilized rhodophyte remains [64]. Homologs of several meiosis-specific genes, including Spo11, Hop1, Hop2, Mnd1, Dmc1 and Msh5, were reported in the genome sequence of the green alga Ostreococcus tauri, suggesting that it has a hitherto undescribed sexual cycle [65]. Encephalitozoon, which is derived from a sexual lineage (Fungi [66]), has homologs of several meiosis-specific genes and only appears to be missing Dmc1, Msh4 and Msh5 among the meiosis-specific genes in our inventory. This may either indicate a hitherto unseen sexual cycle in Encephalitozoon or be representative of a secondarily asexual state, given that meiosis also occurs in some diplokaryotic microsporidia [67]. Giardia intestinalis was previously found to contain five of seven meiosis-specific genes surveyed [1]; we have determined here that Giardia intestinalis has one of two additional meiosis-specific genes (Mer3, but not Reco). Recent analyses indicate that Diplomonads and Parabasalids are closely related [12-16]. The presence of homologs of some meiotic genes in Giardia intestinalis (and the absence of others) may suggest that the parasexual process in which some of these genes were recently shown to act [4] may represent an intermediate or primitive form of recombination that evolved prior to the origin of those missing meiotic genes. However, given the specific relationship of Giardia to Trichomonas and the presence of most of these meiotic genes in T. vaginalis (27 of 29), it is more likely that Giardia intestinalis secondarily lost some meiotic genes and its parasexual homologous recombination [4] is derived from a more typical meiotic recombination. In sum, this inventory of meiotic genes suggests the potential for meiosis in Cryptosporidium, Entamoeba, Cyanidioschyzon, Encephalitozoon and Giardia.

Finally, several other organisms among AFP and protists that are known to be sexual were also included in this inventory of meiotic genes (Table 2). Conserved homologs of meiotic genes are present in the stramenopiles Thalassiosira and Phytophthora. The conserved meiotic genes found in Trypanosoma brucei and Trypanosoma cruzi and the recently discovered evidence for genetic exchange in vitro in these organisms $[68,69]$ together support evidence for a sexual cycle. We also find that the meiotic genes in Saccharomyces are conserved in other fungi, though Gibberella (and possibly, Magnaporthe) is missing the same set of genes that are also absent in its close relative, Neurospora. The meiotic genes found in mammals are generally conserved in other vertebrates, as well as invertebrates. Notably, genes such as $M n d 1$ and $D m c 1$ that are found in vertebrates but missing in Drosophila and Caenorhabditis are present in Schistosoma and Bombyx, which suggest multiple independent lineage-specific losses of these genes during the evolution of animals. Plants and the green alga Chlamydomonas included in our analysis also appear to share a similar complement of meiotic genes.

Of the nine meiosis-specific genes included in our study, only $\operatorname{Rec} 8$ - the meiosis-specific paralog of the Rad21 cohesin - cannot be found in any protists (Table 2). Additional data from other protist lineages will be required to ascertain when $\operatorname{Rec} 8$ and $\operatorname{Rad} 21$ diverged. In any case, Rad21 may perform the meiotic role of Rec8 for homologous chromosome cohesion in sexual protists: although $\operatorname{Rad} 21$ is not meiosis-specific, it has a critical meiotic role, which in the absence of Rec8 may be sufficient for meiosis [70,71].

\section{Conclusions}

We found 27 of 29 meiotic genes in Trichomonas vaginalis, and 21 of these 29 genes are also present in Giardia intestinalis. These 27 meiotic genes must have been present in the common ancestor of Trichomonas and Giardia, and given the highly diverged positions of these lineages among eukaryotes [12-16], each of the genes also must have been present in the common ancestor of all eukaryotes. The conservation of this inventory of meiotic genes across such a diverse group of sexual and putatively asexual eukaryotes allows us to infer that the presence of these genes - particularly the meiosisspecific genes - in putatively asexual eukaryotes indicates the potential for meiosis, at least in their recent ancestors.

The widespread presence of the meiotic genes indicates that the core meiotic machinery is largely universal among extant eukaryotes. Our results show that a substantial fraction of the meiotic machinery has evolved early in eukaryotes (Table 2). The evolution of each of the components of the meiotic machinery early during eukaryotic evolution implies that the interactions among the proteins included in our inventory also predate the divergences of the organisms included here. The proteins inventoried here are involved in creating meiotic double-strand DNA breaks and in subsequent meiotic DNA repair, crossing over, and cohesion of sister chromatids and homologous chromosomes, which when found together are compelling evidence for their potential interaction in processes resembling meiotic recombination. We can use this inventory of conserved meiotic genes as a "meiosis detection toolkit" with which to look in the genomes of putative 
asexuals for homologs of the meiotic machinery. This makes useful $a$ priori data with which to further investigate the occurrence of sexual or parasexual processes in the life cycles of organisms for which sex has not been observed, which may have important ecological and epidemiological implications for some organisms such as abundant or parasitic eukaryotic microorganisms.

\section{Materials and Methods}

\section{Database mining}

Searches through the literature and keyword searches of the National Center for Biotechnology Information (NCBI) protein database revealed homologs of 29 meiotic proteins from various organisms. These protein sequences were used as queries for BLASTp, PSI-BLASTp and tBLASTn searches [72] of the NCBI nonredundant and genomic sequence databases between October 2003 and May 2006. Similarly, meiotic protein homologs were retrieved from the protist genome sequence databases of Giardia intestinalis ([73,74], http://www.mbl.edu/Giardia), Trypanosoma brucei [75], Trypanosoma cruzi [76], Entamoeba histolytica [77], Tetrahymena thermophila [78] and Trichomonas vaginalis strain G3 [9] at The Institute for Genomic Research (TIGR, www.tigr.org/tdb/ euk), Cyanidioschyzon merolae ([79], http://merolae.biol.s.u-tokyo.ac. jp/blast/blast.html), and Thalassiosira pseudonana [80], Phytophthora ramorum and Phytophthora sojae [81] and Chlamydomonas reinhardtii [82] at the Joint Genome Institute (JGI, http://genome.jgi-psf.org/) by either BLAST or keyword searches of annotated proteins. Between November 2003 and May 2006, unannotated nucleotide sequences of meiotic genes were extracted from the genome of Trichomonas vaginalis strain G3 [9] by tBLASTn searches of the database of unannotated sequences (http://tigrblast.tigr.org/er-blast/index. cgi? project $=\mathrm{tvg}$ ) with meiotic protein homologs from other eukaryotes as the queries. Once the sequences for each T. vaginalis gene (Table 2) were mined from the database, putative start and stop codons were inferred on the basis of the inferred translation with reference to pairwise comparisons (BLASTx of GenBank) and multiple sequence alignments of homologous proteins. Sequences were assembled and putative open reading frames annotated using Sequencher ${ }^{\text {TM }} 4.6$ (Genecodes, Ann Arbor MI, USA). We used meiotic gene homologs from T. vaginalis strains NIH-C1 or G3 as queries to search public databases of $T$. vaginalis strain G3 expressed sequence tags (ESTs) by BLASTn (http://cgbc.cgu.edu. tw/est/, now at http://www.trichdb.org/trichdb) and dbEST at NCBI http://www.ncbi.nlm.nih.gov/blast/) in August and October 2005 using BLASTn e-value cutoffs zero to -185 . T. vaginalis meiotic genes were also mapped back to whole genome shotgun (WGS) scaffolds at NCBI by BLASTn in August 2005. Vertebrate orthologs of Mer3 were identified by BLASTp searches of NCBI in May 2007. Pairwise comparisons of the nucleotide sequences and inferred translations of $T$. vaginalis duplicated genes were made using the LAlign and PRSS3 programs (http://www.ch.embnet. org/software/LALIGN_form.html [83] and http://www.ch.embnet.org/software/PRSS_form.html $[84,85])$.

\section{PCR amplification}

Amplification primers designed from the Trichomonas vaginalis strain G3 genome project sequences were used to amplify products for regions including the entire gene of interest and roughly 100200 nucleotides of flanking sequence on either end when possible (Table S1.2 in Supporting Information File S1). In some cases, gene fragments were discovered in the first release of the genome (November 2003) and PCR was used to link the fragments together. Miklós Müller (Rockefeller University, New York) generously provided genomic DNA from Trichomonas vaginalis strain NIH-C1. Genes were amplified from this DNA by PCR with Eppendorf MasterTaq ${ }^{\text {TM }}$ DNA polymerase (Hamburg, Germany) or Stratagene Easy-A ${ }^{\mathrm{TM}}$ DNA polymerase (La Jolla CA, USA), as recommended by the manufacturers, with 10-50 ng DNA, $250 \mu \mathrm{M}$ each dNTP (Invitrogen, Carlsbad CA, USA) and $1 \mu \mathrm{M}$ each primer (synthesized at Integrated DNA Technologies (IDT, Coralville IA, USA)) per reaction. Reaction conditions were $95^{\circ} \mathrm{C}$ for 3 minutes followed by $35-40$ cycles at $92^{\circ} \mathrm{C}$ for $40-$ 90 seconds, $35-55^{\circ} \mathrm{C}$ for $60-90$ seconds and $72^{\circ} \mathrm{C}$ for $90-$ 120 seconds +6 seconds/cycle, then ending at $72^{\circ} \mathrm{C}$ for 57 minutes. PCR products were fractionated and isolated from 1\% low melt: $1 \%$ NuSieve $^{\text {TM }}$ GTG agarose (Fisher [Pittsburgh PA] and BioWhittaker [Walkersville MD]) in $1 \times$ TAE buffer. DNA bands were excised from the gel and cloned directly into the pCR4.0-TOPO ${ }^{\mathrm{TM}}$ vector (Invitrogen) according to the manufacturer's instructions. PCR screening with T3 vs T7 primers was used to identify putative clones by the size of their plasmid inserts, cycling at $94^{\circ} \mathrm{C}$ for 2 minutes followed by 30 cycles at $94^{\circ} \mathrm{C}$ for 1 minute, $57^{\circ} \mathrm{C}$ for 1 minute and $72^{\circ} \mathrm{C}$ for $2-3$ minutes, then ending at $72^{\circ} \mathrm{C}$ for 5 minutes (reagents from Invitrogen, Promega [Madison WI, USA] and Fisher) [86]. At least two clones per PGR product were isolated (Eppendorf FastPlasmid $\mathrm{Kit}^{\mathrm{TM}}$ ) and sequenced (ABI BigDye 3.1 and ABI $3730^{\mathrm{TM}}$, Applied Biosystems, Foster City CA, USA) on both strands using M13 forward/reverse and gene-specific primers (Invitrogen and IDT). All sequences have been deposited in GenBank, accession numbers DQ321757-DQ321785 and DQ485348, as listed in Table S1.2 in Supporting Information File S1. We used the TIGR database predicted translations of July 2005 for $S m c 1$, Smc2, Smc3, Smc4 and Smc5 homologs from T. vaginalis strain G3 for our analyses and did not sequence these from strain NIH-C1.

\section{Phylogenetic analysis}

Phylogenetic inference of the evolutionary relationships of each set of putative meiotic proteins present in $T$. vaginalis and its homologs obtained from public databases was used to assign orthology to the $T$. vaginalis meiotic protein homologs. Multiple alignments of amino acid sequences from complete proteins were initially constructed using ClustalX 1.83 [87], then inspected and adjusted manually using MacClade 4.08 [88]. Only unambiguously aligned amino acid sites were used for phylogenetic analyses. For the alignment of eukaryotic and prokaryotic MutS homologs, sites were selected with GBLOCKS ([89], http://molevol.ibmb. csic.es/Gblocks_server/index.html). Phylogenies are unrooted and also rooted by outgroups when possible using either non-meiotic paralogs in a eukaryotic multigene family, or prokaryotic orthologs. Additional analyses in which systematically problematic sequences were removed were also performed (not shown).

MrBayes3.0b4 [90,91] was used for analyses of each meiotic protein alignment. MrBayes was run for $10^{6}$ generations, with four incrementally heated Markov chains, a sampling frequency of $10^{3}$ generations and the temperature set at 0.5. Among-site substitution rate heterogeneity was corrected using an invariable and eight gamma-distributed substitution rate categories and the WAG model for amino acid substitutions [92], abbreviated herein as WAG+I+8G. The consensus tree topology, the arithmetic mean $\log$-likelihood ( $\operatorname{lnL}$ ) for this topology, and branch support were estimated from the set of sampled trees with the best posterior probabilities. The number of trees included in this set varied among analyses. Means and 95\% confidence intervals for the gamma distribution shape parameter $(\alpha)$ and the proportion of invariable sites $(\mathrm{pI})$ were also estimated for each alignment that was analyzed. These analyses were repeated in MrBayes3.1.2 for the Hop2, Mndl and Spoll datasets with two topological 
constraints that group fungi and opisthokonts (animals+fungi). Bootstrap support for the Hop2, Mnd1, Spo11, Mer3 and Msh datasets was estimated with PROML (with SEQBOOT and CONSENSE in PHYLIP 3.6a3 [93]) for 100 bootstrap replicates using the JTT substitution model [94] and eight categories of gamma-distributed and invarying sites (abbreviated herein as $\mathrm{JTT}+\mathrm{I}+8 \mathrm{G})$, with the coefficient of variation calculated from the alpha parameter estimated by MrBayes3.0b4 for each dataset. Prior to the Bayesian analyses shown (Figure 2 and Figures S1.1-S1.33 in Supporting Information File S1), preliminary analyses (results not shown) were carried out using parsimony and distance methods for the purposes of monitoring the progress of the project and for examining partial sequence data (PAUP*4.0b10 [95] and SEQBOOT, PROTDIST, NEIGHBOR and CONSENSE in PHYLIP 3.6 a3 [93]). Using Tree-Puzzle 5.2 [96] we generated maximum-likelihood distance matrices in which among-site substitution rate heterogeneity was corrected using the JTT+I+8G model (results not shown). Neighbor-joining trees were constructed using NEIGHBOR.

\section{Supporting Information}

\section{Supporting Information File S1}

Found at: doi:10.1371/journal.pone.0002879.s001 (0.96 MB PDF)

\section{References}

1. Ramesh MA, Malik SB, Logsdon JM, Jr. (2005) A phylogenomic inventory of meiotic genes: Evidence for sex in Giardia and an early eukaryotic origin of meiosis. Curr Biol 15: 185-191.

2. Cooper MA, Adam RD, Worobey M, Sterling CR (2007) Population genetics provides evidence for recombination in Giardia. Curr Biol 17: 19841988.

3. Logsdon JM Jr (2008) Evolutionary genetics: sex happens in Giardia. Curr Biol 18: R66-68.

4. Poxleitner MK, Carpenter ML, Mancuso JJ, Wang CJ, Dawson SC, et al. (2008) Evidence for karyogamy and exchange of genetic material in the binucleate intestinal parasite Giardia intestinalis. Science 319: 15301533.

5. Baldauf SL (2003) The deep roots of eukaryotes. Science 300: 1703-1706.

6. Cavalier-Smith T (2002) The phagotrophic origin of eukaryotes and phylogenetic classification of Protozoa. Int J Syst Evol Microbiol 52: 297-354.

7. Raikov IB (1995) Meiosis in protists: recent advances and persisting problems. Eur J Protistol 31: 1-17.

8. Cavalier-Smith T (2002) Origins of the machinery of recombination and sex. Heredity 88: 125-141.

9. Carlton JM, Hirt RP, Silva JC, Delcher AL, Schatz M, et al. (2007) Draft genome sequence of the sexually transmitted pathogen Trichomonas vaginalis. Science 315: 207-212.

10. Keeling PJ, Palmer JD (2000) Parabasalian flagellates are ancient eukaryotes. Nature 405: 635-637.

11. Simpson AGB, Roger AJ (2004) The real 'kingdoms' of eukaryotes. Curr Biol 14: R693-696.

12. Arisue N, Hasegawa M, Hashimoto T (2005) Root of the Eukaryota tree as inferred from combined maximum likelihood analyses of multiple molecular sequence data. Mol Biol Evol 22: 409-420.

13. Simpson AG, Inagaki Y, Roger AJ (2006) Comprehensive multigene phylogenies of excavate protists reveal the evolutionary positions of "primitive" eukaryotes. Mol Biol Evol 23: 615-625.

14. Hampl V, Horner DS, Dyal P, Kulda J, Flegr J, et al. (2005) Inference of the phylogenetic position of Oxymonads based on nine genes: support for Metamonada and Excavata. Mol Biol Evol 22: 2508-2518.

15. Simpson AGB (2003) Cytoskeletal organization, phylogenetic affinities and systematics in the contentious taxon Excavata (Eukaryota). Int J Syst Evol Microbiol 53: 1759-1777.

16. Cavalier-Smith T (2003) The excavate protozoan phyla Metamonada Grasse emend. (Anaeromonadea, Parabasalia, Carpediemonas, Eopharyngia) and Loukozoa emend. (Jakobea, Malawimonas): their evolutionary affinities and new higher taxa. Int J Syst Evol Microbiol 53: 1741-1758.

17. Dacks JB, Walker G, Field MC (2008) Implications of the new eukaryotic systematics for parasitologists. Parasitol Int 57: 97-104.

18. Hampl V, Cepicka I, Flegr J, Tachezy J, Kulda J (2004) Critical analysis of the topology and rooting of the Parabasalian 16S rRNA tree. Mol Phylogenet Evol 32: 711-723.

\section{Acknowledgments}

The authors are grateful to Miklós Müller, Bryant F. McAllister, Robert E. Malone, Marilee A. Ramesh, Jane M. Carlton and Steven A. Sullivan for helpful comments on the manuscript. We are especially indebted to J. M. Carlton (New York University School of Medicine) and the T. vaginalis G3 Genome Project members, The Institute for Genomic Research (TIGR), funded by the NIAID/NIH under cooperative agreement, to laboratories of Petrus Tang (Chang Gung University, Taiwan) and Jan Tachezy (Charles University, Prague, Czech Republic), for T. vaginalis G3 EST data and to the genome projects for Giardia intestinalis (M. Sogin Lab, Marine Biological Lab), Trypanosoma brucei (TIGR). T. cruzi (TIGR), Thalassiosira (Joint Genome Institute), P. sojae (JGI), P. ramorum (JGI) and Chlamydomonas (JGI) for making sequence data available prior to publication. Thanks to M. A. Ramesh for isolation and sequence of Giardia Rad18, to Robert B. Moore for partial T. vaginalis Spo11 sequence, to Justine M. Olszewski for help with BLAST analyses, and to Nicole M. Adams for help with sequencing.

\section{Author Contributions}

Conceived and designed the experiments: JML. Performed the experiments: SBM AWP LMS AMS. Analyzed the data: SBM AWP LMS AMS JML. Wrote the paper: SBM AWP AMS JML.

19. Kleina P, Bettim-Bandinelli J, Bonatto SL, Benchimol M, Bogo MR (2004) Molecular phylogeny of Trichomonadidae family inferred from ITS-1, 5.8S rRNA and ITS-2 sequences. Int J Parasitol 34: 963-970.

20. Gerbod D, Sanders E, Moriya S, Noel C, Takasu H, et al. (2004) Molecular phylogenies of Parabasalia inferred from four protein genes and comparison with rRNA trees. Mol Phylogenet Evol 31: 572-580.

21. Ohkuma M, Iida T, Ohtoko K, Yuzawa H, Noda S, et al. (2005) Molecular phylogeny of Parabasalids inferred from small subunit rRNA sequences, with emphasis on the Hypermastigea. Mol Phylogenet Evol 35: 646-655.

22. Keeling PJ (2002) Molecular phylogenetic position of Trichomitopsis termopsidis (Parabasalia) and evidence for the Trichomitopsiinae. Eur J Protistol 38: 279-286.

23. Hampl V, Vrlik M, Cepicka I, Pecka Z, Kulda J, et al. (2006) Affiliation of Cochlosoma to trichomonads confirmed by phylogenetic analysis of the smallsubunit rRNA gene and a new family concept of the order Trichomonadida. Int J Syst Evol Microbiol 56: 305-312.

24. McGlelland RS, Sangare L, Hassan WM, Lavreys L, Mandaliya K, et al. (2007) Infection with Trichomonas vaginalis increases the risk of HIV-1 acquisition. J Infect Dis 195: 698-702.

25. Sutton M, Sternberg M, Koumans EH, McQuillan G, Berman S, et al. (2007) The prevalence of Trichomonas vaginalis infection among reproductive-age women in the United States, 2001-2004. Clin Infect Dis 45: 1319-1326.

26. Johnston VJ, Mabey DC (2008) Global epidemiology and control of Trichomonas vaginalis. Curr Opin Infect Dis 21: 56-64.

27. Schwebke JR, Barrientes FJ (2006) Prevalence of Trichomonas vaginalis isolates with resistance to metronidazole and tinidazole. Antimicrob Agents Chemother 50: 4209-4210.

28. Cleveland LR (1947) The origin and evolution of meiosis. Science 105: 287-280.

29. Cleveland LR (1951) Hormone-induced sexual cycles of flagellates. Journal of Morphology 88: 385-439.

30. Cleveland LR (1956) Brief accounts of the sexual cycles of the flagellates of Cryptocercus. The Journal of Protozoology 3: 161-180.

31. Tibayrenc M, Kjellberg F, Ayala FJ (1990) A clonal theory of parasitic protozoa: the population structures of Entamoeba, Giardia, Leishmania, Naegleria, Plasmodium, Trichomonas, and Trypanosoma and their medical and taxonomical consequences. Proc Natl Acad Sci U S A 87: 2414-2418.

32. Hampl V, Pavlicek A, Flegr J (2001) Construction and bootstrap analysis of DNA fingerprinting-based phylogenetic trees with the freeware program FreeTree: application to Trichomonad parasites. Int J Syst Evol Microbiol 51: 731-735.

33. Hampl V, Vanacova S, Kulda J, Flegr J (2001) Concordance between genetic relatedness and phenotypic similarities of Trichomonas vaginalis strains. BMC Evol Biol 1: 11 .

34. Silva JC, Bastida F, Bidwell SL, Johnson PJ, Carlton JM (2005) A potentially functional mariner transposable element in the protist Trichomonas vaginalis. Mol Biol Evol 22: 126-134. 
35. Pritham EJ, Putliwala T, Feschotte C (2007) Mavericks, a novel class of giant transposable elements widespread in eukaryotes and related to DNA viruses. Gene 390: 3-17.

36. Feschotte C, Pritham EJ (2007) DNA transposons and the evolution of eukaryotic genomes. Annu Rev Genet 41: 331-368.

37. Lyons EJ, Carlton JM (2004) Mind the gap: bridging the divide between clinical and molecular studies of the Trichomonads. Trends Parasitol 20: 204-207.

38. Arkhipova I, Meselson M (2005) Deleterious transposable elements and the extinction of asexuals. Bioessays 27: 76-85.

39. Arkhipova IR (2005) Mobile genetic elements and sexual reproduction. Cytogenet Genome Res 110: 372-382.

40. Pereira-Neves A, Ribeiro KC, Benchimol M (2003) Pseudocysts in Trichomonads - new insights. Protist 154: 313-329.

41. Ribeiro KC, Monteiro-Leal LH, Benchimol M (2000) Contributions of the axostyle and flagella to closed mitosis in the protists Tritrichomonas foetus and Trichomonas vaginalis. J Eukaryot Microbiol 47: 481-492.

42. Drmota T, Kral J (1997) Karyotype of Trichomonas vaginalis. Europ J Protistol 33: 131-135.

43. Honigberg BM, Brugerolle G (1989) Chapter 3: Structure. In: Honigberg BM, ed (1989) Trichomonads parasitic in humans. New York: Springer-Verlag. pp $5-35$.

44. Birky CW Jr (2005) Sex: is Giardia doing it in the dark? Curr Biol 15: R56-58.

45. Dacks JB, Doolittle WF (2001) Reconstructing/deconstructing the earliest eukaryotes: how comparative genomics can help. Cell 107: 419-425.

46. Wolfe K (2004) Evolutionary genomics: yeasts accelerate beyond BLAST. Curr Biol 14: R392-394.

47. Chuma I, Tosa Y, Taga M, Nakayashiki H, Mayama S (2003) Meiotic behavior of a supernumerary chromosome in Magnaporthe oryzae. Curr Genet 43: 191-198.

48. Birky CW Jr (1996) Heterozygosity, heteromorphy, and phylogenetic trees in asexual eukaryotes. Genetics 144: 427-437.

49. Malik SB, Ramesh MA, Hulstrand AM, Logsdon JM Jr (2007) Protist homologs of the meiotic Spo11 gene and topoisomerase VI reveal an evolutionary history of gene duplication and lineage-specific loss. Mol Biol Evol 24: 2827-2841.

50. Cobbe N, Heck MM (2004) The evolution of SMC proteins: phylogenetic analysis and structural implications. Mol Biol Evol 21: 332-347.

51. Chen YK, Leng CH, Olivares H, Lee MH, Chang YC, et al. (2004) Heterodimeric complexes of Hop2 and Mnd1 function with Dmc1 to promote meiotic homolog juxtaposition and strand assimilation. Proc Natl Acad Sci U S A 101: 10572-10577.

52. Petukhova GV, Pezza RJ, Vanevski F, Ploquin M, Masson JY, et al. (2005) The Hop2 and Mnd1 proteins act in concert with Rad51 and Dmcl in meiotic recombination. Nat Struct Mol Biol 12: 449-453.

53. Marcon E, Moens PB (2005) The evolution of meiosis: recruitment and modification of somatic DNA-repair proteins. Bioessays 27: 795-808.

54. Villeneuve AM, Hillers KJ (2001) Whence meiosis? Cell 106: 647-650.

55. Schurko AM, Logsdon JM Jr (2008) Using a meiosis detection toolkit to investigate ancient asexual "scandals" and the evolution of sex. Bioessays 30: $579-589$.

56. Snowden T, Acharya S, Butz C, Berardini M, Fishel R (2004) hMSH4-hMSH5 recognizes Holliday junctions and forms a meiosis-specific sliding clamp that embraces homologous chromosomes. Mol Cell 15: 437-451.

57. Bishop DK, Zickler D (2004) Early decision; meiotic crossover interference prior to stable strand exchange and synapsis. Cell 117: 9-15.

58. Borner GV, Kleckner N, Hunter N (2004) Crossover/noncrossover differentiation, synaptonemal complex formation, and regulatory surveillance at the leptotene/zygotene transition of meiosis. Cell 117: 29-45.

59. Cleveland LR (1947) Sex produced in the protozoa of Cryptocercus by molting. Science 105: 16-17.

60. Haig D (1993) Alternatives to meiosis: the unusual genetics of red algae, microsporidia, and others. J Theor Biol 163: 15-31.

61. Andersen RA, Anderson OR, Banner FT, Barta JR, Boltovskoy D, et al. (2000) The Illustrated Guide to the Protozoa; Lee JJ, Leedale GF, Bradbury P, eds (2000) Society of Protozoologists.

62. Watkins RF, Gray MW (2008) Sampling gene diversity across the supergroup Amoebozoa: large EST data sets from Acanthamoeba castellanii, Hartmannella vermiformis, Physarum polycephalum, Hyperamoeba dachnaya and Hyperamoeba sp. Protist 159: 269-281.

63. Mochizuki K, Novatchkova M, Loidl J (2008) DNA double-strand breaks, but not crossovers, are required for the reorganization of meiotic nuclei in Tetrahymena. J Cell Sci.

64. Butterfield NJ, Knoll AH, Swett K (1990) A bangiophyte red alga from the Proterozoic of arctic Canada. Science 250: 104-107.

65. Derelle E, Ferraz G, Rombauts S, Rouze P, Worden AZ, et al. (2006) Genome analysis of the smallest free-living eukaryote Ostreococcus tauri unveils many unique features. Proc Natl Acad Sci U S A 103: 11647-11652.

66. Hirt RP, Logsdon JM Jr, Healy B, Dorey MW, Doolittle WF, et al. (1999) Microsporidia are related to Fungi: evidence from the largest subunit of RNA polymerase II and other proteins. Proc Natl Acad Sci U S A 96: 580-585.

67. Nassonova ES, Smirnov AV (2005) Synaptonemal complexes as evidence for meiosis in the life cycle of the monomorphic diplokaryotic microsporidium Paranosema grylli. European Journal of Protistology 41: 175-181.
68. Gaunt MW, Yeo M, Frame IA, Stothard JR, Carrasco HJ, et al. (2003) Mechanism of genetic exchange in American trypanosomes. Nature 421: 936-939.

69. MacLeod A, Tweedie A, McLellan S, Hope M, Taylor S, et al. (2005) Allelic segregation and independent assortment in T. brucei crosses: proof that the genetic system is Mendelian and involves meiosis. Mol Biochem Parasitol 143: $12-19$.

70. Xu H, Beasley M, Verschoor S, Inselman A, Handel MA, et al. (2004) A new role for the mitotic RAD21/SCG1 cohesin in meiotic chromosome cohesion and segregation in the mouse. EMBO Rep 5: 378-384.

71. Prieto I, Pezzi N, Buesa JM, Kremer L, Barthelemy I, et al. (2002) STAG2 and Rad21 mammalian mitotic cohesins are implicated in meiosis. EMBO Rep 3: 543-550.

72. Altschul SF, Madden TL, Schaffer AA, ZhangJ, Zhang Z, et al. (1997) Gapped BLAST and PSI-BLAST: a new generation of protein database search programs. Nucleic Acids Res 25: 3389-3402.

73. McArthur AG, Morrison HG, Nixon JE, Passamaneck NQ Kim U, et al. (2000) The Giardia genome project database. FEMS Microbiol Lett 189: 271-273.

74. Morrison HG, McArthur AG, Gillin FD, Aley SB, Adam RD, et al. (2007) Genomic minimalism in the early diverging intestinal parasite Giardia lamblia. Science 317: 1921-1926.

75. Berriman M, Ghedin E, Hertz-Fowler C, Blandin G, Renauld H, et al. (2005) The genome of the African trypanosome Trypanosoma brucei. Science 309: 416-422.

76. El-Sayed NM, Myler PJ, Bartholomeu DC, Nilsson D, Aggarwal G, et al (2005) The genome sequence of Trypanosoma cruzi, etiologic agent of Chagas disease. Science 309: 409-415

77. Loftus B, Anderson I, Davies R, Alsmark UC, Samuelson J, et al. (2005) The genome of the protist parasite Entamoeba histolytica. Nature 433: 865-868.

78. Eisen JA, Coyne RS, Wu M, Wu D, Thiagarajan M, et al. (2006) Macronuclear genome sequence of the ciliate Tetrahymena thermophila, a model eukaryote. PLoS Biol 4.

79. Matsuzaki M, Misumi O, Shin IT, Maruyama S, Takahara M, et al. (2004) Genome sequence of the ultrasmall unicellular red alga Cyanidioschyzon merolae 10D. Nature 428: 653-657.

80. Armbrust EV, Berges JA, Bowler C, Green BR, Martinez D, et al. (2004) The genome of the diatom Thalassiosira pseudonana: ecology, evolution, and metabolism. Science 306: 79-86.

81. Tyler BM, Tripathy S, Zhang X, Dehal P, Jiang RHY, et al. (2006) Phytophthora genome sequences uncover evolutionary origins and mechanisms of pathogenesis. Science 313: 1261-1266.

82. Merchant SS, Prochnik SE, Vallon O, Harris EH, Karpowicz SJ, et al. (2007) The Chlamydomonas genome reveals the evolution of key animal and plant functions. Science 318: 245-250

83. Huang XO, Miller W (1991) A time-efficient, linear-space local similarity algorithm. Advances in Applied Mathematics 12: 337-357.

84. Smith TF, Waterman MS (1981) Identification of common molecular subsequences. J Mol Biol 147: 195-197.

85. Pearson WR, Lipman DJ (1988) Improved tools for biological sequence comparison. Proc Natl Acad Sci U S A 85: 2444-2448.

86. Sandhu GS, Precup JW, Kline BC (1989) Rapid one-step characterization of recombinant vectors by direct analysis of transformed Escherichia coli colonies. Biotechniques 7: 689-690

87. Chenna R, Sugawara H, Koike T, Lopez R, Gibson TJ, et al. (2003) Multiple sequence alignment with the Clustal series of programs. Nucleic Acids Res 31: 3497-3500.

88. Maddison WP, Maddison DR (2005) MacClade. 4.07 ed. Sunderland, MA: Sinauer Associates.

89. Castresana J (2000) Selection of conserved blocks from multiple alignments for their use in phylogenetic analysis. Mol Biol Evol 17: 540-552.

90. Huelsenbeck JP, Ronquist F (2001) MRBAYES: Bayesian inference of phylogenetic trees. Bioinformatics 17: 754-755.

91. Ronquist F, Huelsenbeck JP (2003) MrBayes 3: Bayesian phylogenetic inference under mixed models. Bioinformatics 19: 1572-1574.

92. Whelan S, Goldman N (2001) A general empirical model of protein evolution derived from multiple protein families using a maximum-likelihood approach. Mol Biol Evol 18: 691-699.

93. Felsenstein J (2005) PHYLIP, Phylogeny Inference Package. 3.6a3 ed. University of Washington: Seattle.

94. Jones DT, Taylor WR, Thornton JM (1992) The rapid generation of mutation data matrices from protein sequences. Comput Appl Biosci 8: 275-282.

95. Swofford DL (2003) PAUP*: Phylogenetic Analysis Using Parsimony (*and Other Methods). 4.0b10 ed. Sunderland, Massachusetts: Sinauer Associates.

96. Schmidt HA, Strimmer K, Vingron M, von Haeseler A (2002) TREEPUZZLE: maximum likelihood phylogenetic analysis using quartets and parallel computing. Bioinformatics 18: 502-504.

97. Whitby MC (2005) Making crossovers during meiosis. Biochem Soc Trans 33: 1451-1455.

98. Neale MJ, Keeney S (2006) Clarifying the mechanics of DNA strand exchange in meiotic recombination. Nature 442: 153-158.

99. Kunz C, Schar P (2004) Meiotic recombination: sealing the partnership at the junction. Curr Biol 14: R962-964. 
100. Smith KN, Nicolas A (1998) Recombination at work for meiosis. Curr Opin Genet Dev 8: 200-211.

101. Cobbe N, Heck MM (2000) Review: SMCs in the world of chromosome biology- from prokaryotes to higher eukaryotes. J Struct Biol 129: 123-143.

102. Richard GF, Kerrest A, Lafontaine I, Dujon B (2005) Comparative genomics of hemiascomycete yeasts: genes involved in DNA replication, repair, and recombination. Mol Biol Evol 22: 1011-1023.

103. Keeney S, Giroux CN, Kleckner N (1997) Meiosis-specific DNA double-strand breaks are catalyzed by Spo11, a member of a widely conserved protein family. Cell 88: 375-384

104. Nichols MD, DeAngelis K, Keck JL, Berger JM (1999) Structure and function of an archaeal topoisomerase VI subunit with homology to the meiotic recombination factor Spo11. EMBO J 18: 6177-6188.

105. Merino ST, Cummings WJ, Acharya SN, Zolan ME (2000) Replicationdependent early meiotic requirement for Spo11 and Rad50. Proc Natl Acad Sci U S A 97: 10477-10482.

106. Moreau S, Ferguson JR, Symington LS (1999) The nuclease activity of Mre11 is required for meiosis but not for mating type switching, end joining, or telomere maintenance. Mol Cell Biol 19: 556-566.

107. Haber JE (1998) The many interfaces of Mre11. Cell 95: 583-586.

108. Hopfner KP, Karcher A, Shin D, Fairley C, Tainer JA, et al. (2000) Mre11 and Rad50 from Pyrococcus furiosus: cloning and biochemical characterization reveal an evolutionarily conserved multiprotein machine. J Bacteriol 182: 6036-6041.

109. Yildiz O, Kearney H, Kramer BC, Sekelsky JJ (2004) Mutational analysis of the Drosophila DNA repair and recombination gene mei-9. Genetics 167: 263-273.

110. Bhui-Kaur A, Goodman MF, Tower J (1998) DNA mismatch repair catalyzed by extracts of mitotic, postmitotic, and senescent Drosophila tissues and involvement of mei-9 gene function for full activity. Mol Cell Biol 18: $1436-1443$.

111. Aravind L, Koonin EV (1998) The HORMA domain: a common structural denominator in mitotic checkpoints, chromosome synapsis and DNA repair. Trends Biochem Sci 23: 284-286.

112. Tsubouchi H, Roeder GS (2002) The Mndl protein forms a complex with Hop2 to promote homologous chromosome pairing and meiotic double-strand break repair. Mol Cell Biol 22: 3078-3088.

113. Gerton JL, DeRisi JL (2002) Mndlp: an evolutionarily conserved protein required for meiotic recombination. Proc Natl Acad Sci U S A 99: 6895-6900.

114. Van Dyck E, Stasiak AZ, Stasiak A, West SC (1999) Binding of double-strand breaks in DNA by human Rad52 protein Nature 398: 728-731.
115. West SC (2003) Molecular views of recombination proteins and their control. Nat Rev Mol Cell Biol 4: 435-445.

116. Masson JY, West SC (2001) The Rad51 and Dmc1 recombinases: a nonidentical twin relationship. Trends Biochem Sci 26: 131-136.

117. Bishop DK, Park D, Xu L, Kleckner N (1992) DMC1: a meiosis-specific yeast homolog of $E$. coli recA required for recombination, synaptonemal complex formation, and cell cycle progression. Cell 69: 439-456.

118. Stassen NY, Logsdon JM Jr, Vora GJ, Offenberg HH, Palmer JD, et al. (1997) Isolation and characterization of rad51 orthologs from Coprinus cinereus and Lycopersicon esculentum, and phylogenetic analysis of eukaryotic recA homologs. Curr Genet 31: 144-157.

119. Borts RH, Chambers SR, Abdullah MF (2000) The many faces of mismatch repair in meiosis. Mutat Res 451: 129-150.

120. Nakagawa T, Ogawa H (1999) The Saccharomyces cerevisiae MER3 gene, encoding a novel helicase-like protein, is required for crossover control in meiosis. EMBO J 18: 5714-5723.

121. Mazina OM, Mazin AV, Nakagawa T, Kolodner RD, Kowalczykowski SC (2004) Saccharomyces cerevisiae Mer3 helicase stimulates 3'-5' heteroduplex extension by Rad51; implications for crossover control in meiotic recombination. Cell 117: 47-56.

122. Chen G, Zhang W, Timofejeva L, Gerardin Y, Ma H (2005) The Arabidopsis ROCK-N-ROLLERS gene encodes a homolog of the yeast ATP-dependent DNA helicase MER3 and is required for normal meiotic crossover formation. Plant J 43: 321-334.

123. Losada A, Hirano T (2005) Dynamic molecular linkers of the genome: the first decade of SMC proteins. Genes Dev 19: 1269-1287.

124. Weitzer S, Lehane C, Uhlmann F (2003) A model for ATP hydrolysisdependent binding of cohesin to DNA. Curr Biol 13: 1930-1940.

125. van der Laan R, Roest HP, Hoogerbrugge JW, Smit EM, Slater R, et al. (2000) Characterization of $m R A D 18 S c$, a mouse homolog of the yeast postreplication repair gene RAD18. Genomics 69: 86-94.

126. Klein F, Mahr P, Galova M, Buonomo SB, Michaelis C, et al. (1999) A central role for cohesins in sister chromatid cohesion, formation of axial elements, and recombination during yeast meiosis. Cell 98: 91-103.

127. Wang F, Yoder J, Antoshechkin I, Han M (2003) Caenorhabditis elegans EVL-14/ PDS-5 and SCC-3 are essential for sister chromatid cohesion in meiosis and mitosis. Mol Cell Biol 23: 7698-7707. 